\title{
Ecological assessment of noise impact of dry transformer substations on the environment
}

\author{
Sarkis Barseghyan*, Arman Hayrapetyan, and Armen Kirakosyan \\ National Polytechnic University of Armenia, Institute of Energy Electrical Engineering, 0009 \\ Yerevan, 105 Teryam Str., Amenia
}

\begin{abstract}
At present, special attention is paid to assessing the negative impact of power facilities on the environment, including the impact of noise generated by power equipment. Power transformers are one of the sources of noise for industrial areas and the surrounding area. The noise of transformers is caused both by the vibration of its active part and by the fans of the cooling system, which is amplified by resonance phenomena in its individual elements. The presented work provides an environmental assessment of the noise impact of transformer substations. The noise impact of a transformer substation is considered on the example of three dry transformers in the area immediately adjacent to the living space. A new corrected approach was developed and tested for calculating the sound power level for dry transformers with the MatLab software package. An assessment of the noise impact of the projected transformer substation to install three dry transformers was the voltage class of which is $400 \mathrm{kVA}$, and one has $1000 \mathrm{kVA}$ for the territory immediately adjacent to the living area was made. In our researches, the regulated noise characteristic for transformers is the corrected sound power level, which is indicated in the technical characteristics of the transformer. Calculations on non-standard nominal rated powers were carried out.
\end{abstract}

Power transformer substations (TS) are the main elements of the electrical network and are used to convert electricity from one voltage to another, communication between individual sections of the network, voltage regulation and power flows [1]. But during their operation, a negative impact on the environment is possible, the lion's share of which is due to noise [2]. An increase in the noise intensity of transformers is caused by the vibration of its active part, as well as the fans of the cooling system. Resonance phenomena arising in its individual elements have a significant effect on the noise of a transformer $[3,5]$. There is a direct relationship between the sound power levels of transformers and their electrical power. This dependence can change with a change in design and materials, induction or mass, while maintaining the same level of other parameters.

The specificity of dry transformers with a capacity of up to $1000 \mathrm{kVA}$ is a wide variety of designs of magnetic systems, among which one can name laminated, wound, butt (glued from two halves), symmetric spatial, with many modifications due to the types of joints, types of mixtures, the nature of pressing, etc.

\footnotetext{
* Corresponding author: sako.barsegyan@,mail.ru
} 
A significant reduction in the sound level of transformers is achieved by impregnation and gluing of the magnetic system with materials based on epoxy resins [1]. Three-phase dry transformers with a laminated magnetic system are most common. The noise of the active part of such transformers without a casing is low. However, it rises sharply for a fully assembled transformer with a casing, which increases the transformer sound emission surface and, moreover, does not have sufficient rigidity, being made of sheet steel [6].

To assess the noise impact of the projected TS, we calculated the sound pressure level in the area adjacent to residential areas. According to the terms of the task, the TS is located in a concrete building with dimensions of $6 \times 6 \times 4 \mathrm{~m}$, a metal door $2 \times 1 \mathrm{~m}$, and two metal gates with dimensions of $2.5 \times 3 \mathrm{~m}$. In this transformer substation, it is allowed to install three dry transformers, the voltage class of which is $10 / 0.4 \mathrm{kV}$. At the same time, two of them have a rated power of $400 \mathrm{kVA}$, and one - $1000 \mathrm{kVA}$ [7].

The regulated noise characteristic for transformers is the corrected sound power level (LpA), dBA, which is indicated in the technical characteristics of the transformer [3].

To date, the available technical conditions for assessing the noise impact of both dry and oil-immersed transformers are calculated for specific point power values of the transformers themselves. In practice, however, it becomes necessary to determine the level of noise exposure for transformers with non-standard power values.

The problem is exacerbated when transformers of standard capacities are used at partial load. But when designing TS, it becomes necessary to take into account the non-standard loads of transformers. Based on this, we have developed and tested a new corrected approach for calculating the sound power level for dry transformers.

Table 1. The corrected sound power levels of transformers with natural air and oil circulation (cooling system type M).

\begin{tabular}{|c|c|c|c|}
\hline $\begin{array}{c}\text { Typical } \\
\text { power, kVA }\end{array}$ & $\begin{array}{c}\text { Corrected sound power } \\
\text { level for voltage classes } \\
\mathbf{6 - 3 5} \mathbf{~ k V}, \\
\mathbf{L p A}(\mathbf{d B A})\end{array}$ & $\begin{array}{c}\text { Typical } \\
\text { power, } \mathbf{k V A}\end{array}$ & $\begin{array}{c}\text { Corrected sound power } \\
\text { level for voltage classes } \\
\mathbf{6 - 3 5} \mathbf{~ k V}, \mathbf{L p A} \text { (dBA) }\end{array}$ \\
\hline 100 & 59 & 630 & 70 \\
\hline 160 & 62 & 1000 & 73 \\
\hline 250 & 65 & 1600 & 75 \\
\hline 400 & 68 & 2500 & 76 \\
\hline
\end{tabular}

To solve this technical problem, the existing tabular values (table 1) were taken as a basis for correcting the noise effect, but with our modifications [4]. The essence of the latter consisted in modifying the noise effect with the involvement of a larger number of point values and, based on the latter, using the MatLab software package, obtain a curve (figure 1), which is approximated by formula (1). 


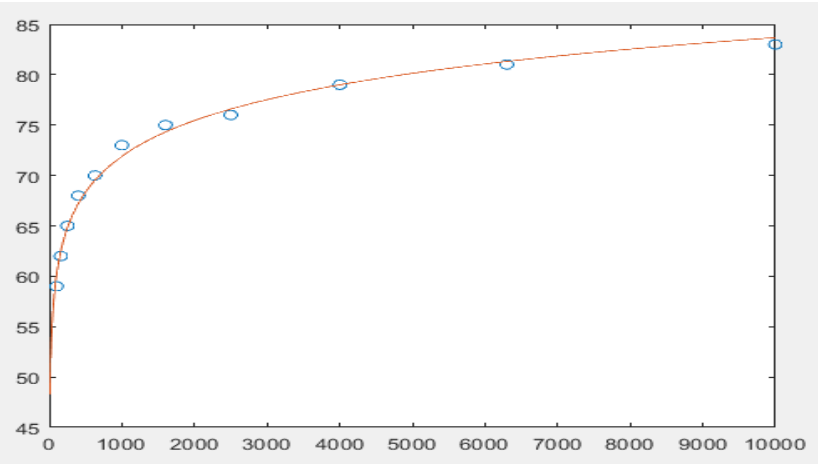

Figure 1. Curve modifications sound effect involving a larger number of point values using MatLab software package.

The presented formula is universal for the operation of transformers with excellent load capacity:

$$
L p A=36.57+5.12 \cdot \ln \left(S_{D T}\right)
$$

where $\boldsymbol{S}_{\boldsymbol{D} \boldsymbol{T}}$ is the power of a dry transformer, kVA.

It is accepted that the sound pressure level in a room with several noise sources is determined by the formula [8], into which we introduce a newly developed component (1) in order to obtain a real picture of the increased noise effect:

$$
L=10 \lg \left(\sum_{i=1}^{m} \frac{10^{0,1 \cdot L_{p A i} \cdot x_{i} \Phi_{i}}}{\Omega \cdot r_{i}^{2}}+\frac{4}{k B} \sum_{i=1}^{n} 10^{0,1 \cdot L_{p A i}}\right)
$$

where $\boldsymbol{L}_{p A i}$ is the octave sound power level of the $i$-th source, $\mathrm{dB}$;

$\chi$ is a coefficient that takes into account the influence of the near field;

$\boldsymbol{\Phi}$ is directivity factor of the noise source;

$\boldsymbol{\Omega}$ is the spatial angle of the source radiation, $\mathrm{rad}$;

$\boldsymbol{\alpha}_{\boldsymbol{a} v}$ is average sound absorption coefficient

$r$ is the distance from the acoustic center of the noise source to the design point, $m$;

$\boldsymbol{k}$ is coefficient taking into account the violation of the diffuseness of the sound field in the room;

$\boldsymbol{B}$ is the acoustic constant of the room, $\mathrm{m}^{2}$;

$\boldsymbol{A}$ is the equivalent sound absorption area, $\mathrm{m}^{2}$.

The calculation of the noise pressure was carried out according to the new modification (2) in accordance with $[8]: \chi=2 ; \boldsymbol{\Phi}=1 ; \boldsymbol{\Omega}=2 \pi \mathrm{rad} ; \boldsymbol{r}=1 \mathrm{~m} ; \boldsymbol{k}=1.25 ; \boldsymbol{\alpha}_{\boldsymbol{a} v}=0.15 ; \boldsymbol{S}=$ $64 \mathrm{~m}^{2} ; \boldsymbol{A}=9.6 \mathrm{~m}^{2} ; \boldsymbol{B}=11.3 \mathrm{~m}^{2}$.

As a result of the calculation, the noise value inside the TS building is obtained, which is equal to $\mathrm{L}=75.3 \mathrm{dBA}$. Next, the sound power level of the noise $\boldsymbol{L}_{\boldsymbol{p} \boldsymbol{A i}}^{\text {past }}$, dBA, passed through the fence into the territory, was determined using the formula:

$$
L_{p A i}^{p a s t}=10 \lg \sum_{i=1}^{n} 10^{0,1 \cdot L_{p A i}}-10 \lg B_{\text {noise }}-10 \lg K+\lg S-R
$$

where $\boldsymbol{L}_{\boldsymbol{p} A \boldsymbol{i}}$ is the sound power level of the $i$-th source, dBA;

$\boldsymbol{B}_{\text {noise }}$ is acoustic constant of the room with the source (s) of noise, $\mathrm{m} 2$;

$\boldsymbol{S}$ is the area of the fence, $\mathrm{m} 2$;

$\boldsymbol{R}$ - airborne noise insulation by a fence, $\mathrm{dBA}$.

For calculating of the sound power level according to our modification (2), the following values were taken for a $15-\mathrm{cm}$ plastered wall: $\boldsymbol{L}_{\boldsymbol{p A i}}=80 \mathrm{dBA}, \boldsymbol{B}_{\text {noise }}=11.3 \mathrm{~m}^{2}, \boldsymbol{S}=$ $24 \mathrm{~m}^{2}, \boldsymbol{R}=47 \mathrm{dBA}$.

As a result of the calculation, it turns out that the amount of noise from the outside of the TS building is $\boldsymbol{L}_{\boldsymbol{p} \boldsymbol{A i}}^{\text {past }}=30.6 \mathrm{dBA}$. In this case, the permissible noise level in the area adjacent to the building, in accordance with sanitary standards 2.2.4/2.1.8.562-96 "Noise at 
workplaces, in premises of residential, public buildings and on the territory of residential development" is $55 \mathrm{dBA}$, which creates a TS with a voltage class of $10 / 0.4 \mathrm{kV}$. Therefore, special measures to reduce noise are not required.

Thus, the proposed modified method for calculating the noise pressure and sound power makes it possible to have a real picture of the noise background during the operation of TS near populated areas.

\section{Reference}

1. A.A. Kirakosyan, S.G. Nersesyan, A.Kh. Airapetyan, Yu.A. Oganesyan, Bulletin of the Engineering Academy of Armenia., IV (4), 35-37 (2007)

2. E.N. Sosnina, O.V. Masleeva, R.Sh. Bedretdinov, I.A. Lipuzhin, Bulletin of BSTU after V.G. Shukhova, 4, 168 (2013)

3. D.F. Lazaroiu, The noise of electrical machines and transformers: trans. from room (Energiya, Moscow,1973)

4. A.A. Kirakosyan, O.N. Gasparyan, Application of MATLAB in scientific and technical calculations (Engineer, Yerevan, 2008)

5. I.G. Shubov, Noise and Vibration of Electrical Machines: 2nd ed., Rev. and add ( Energoatomizdat, Leningrad,1986)

6. V.B. Tupov, Reducing noise from power equipment (Publishing house of MPEI, Moscow 2005)

7. Uralelectrotyazhmash Energomash - Yekaterinburg [Electronic resource]. - URL: http://www.uetm.ru.

8. Noise protection SNiP 23.03.2003 (Publishing house of the State Committee of the Russian Federation for construction and housing and communal services (Gosstroy of Russia), Moscow, 2004) 